\title{
Leatherwork: a possible hazard to reproduction
}

\author{
MICHAEL CLARKE, ELIZABETH S MASON
}

\begin{abstract}
A retrospective study was carried out aimed at eliciting the causes of perinatal death in Leicestershire between 1976 and 1982. Case notes were reviewed and the mothers interviewed in over 1000 cases. An analysis of maternal occupations showed that leatherworkers were at increased risk of having a perinatal death, particularly from congenital malformations and macerated stillbirths, even when compared with other manual workers in the same social class. The excess risk occurred in all towns of the county where leatherwork was undertaken.

Further investigation is needed of the materials used in the leather industry in order to ensure that risks are minimised. Fecund women working in the industry should be informed of any residual risk if these findings are confirmed.
\end{abstract}

\section{Introduction}

Recently increased concern has been expressed for the welfare of pregnant women at work. ${ }^{1}$ Reproductive hazards are thought to exist in many industrial settings, but often this view is based on studies in animals and evidence in man is sadly lacking. ${ }^{2}$ Workers in Finland, however, have suggested that women employed in particular industries may have increased risks of spontaneous abortion. ${ }^{3}$ We report the results of a retrospective study carried out in Leicestershire.

\section{Methods}

Since 1 January 1976 we have been undertaking a case-control study of perinatal deaths occurring to Leicestershire women. Perinatal

Department of Community Health, Leicester University Medical School, Clinical Sciences Building, Leicester Royal Infirmary, PO Box 65, Leicester LE2 7LX

MICHAEL CLARKE, DPH, FFCM, professor of epidemiology

ELIZABETH S MASON, BSC, MPHIL, research assistant

Correspondence and requests for reprints to: Professor M Clarke. death is defined as a stillbirth or death occurring within the first week of life. Between 1976 and 1982 details of the mothers' medical, obstetric, and social histories were recorded from the case notes and interviews with the women concerned. The control for each case was selected as the next live birth occurring at the place, or intended place, of delivery of the case. The only matching that occurred was that which took place inadvertently due to the method of selecting controls. ${ }^{4}$ All maternal and paternal occupations and industries (or for unmarried women the occupation and industry of the chief economic supporter) were recorded at the interview with the mother and later coded to the 1970 classification of occupations. ${ }^{5}$ The occupations were then grouped into the 27 orders which approximate to broad industrial groups-for example, textile workers; food, drink, and tobacco workers; sales workers; clerical workers; and so forth. The analyses below relate to the maternal occupations reported during the pregnancy in question.

\section{Results}

Between 1976 and 1982 women resident in Leicestershire were delivered of 75000 infants, 1187 of whom were stillborn or died within the first week of life. Of the mothers of these perinatal deaths, $671\left(56^{\circ}{ }_{0}\right)$ were employed outside the home at some time during the pregnancy. This proportion of women in paid employment was very close to that reported for married women aged 20-44 years in Great Britain between 1976 and $1981 .^{6}$

Inspection of the odds ratio estimates of the risk of perinatal death in each of the 27 occupational orders disclosed four orders with high ratios when compared with all other workers (table I). Occupational orders VII (engineering and allied trades; not elsewhere classified), XIV (makers of other products), and XXIII (service, sport, and recreation workers) each covered a wide range of occupations and in no case were the acceptable levels of statistical significance achieved. Occupational order IX-leatherworkers-however, were of particular interest because it was unlikely that the observed excess risk had occurred by chance and because of the specificity of the working material and environment. This is exemplified by the fact that the category included only four occupational groups- $(a)$ tanners (there were none in the sample); $(b)$ shoemakers and repairers; (c) cutters, lasters, sewers, footwear and related workers; and $(d)$ leather product makers, not classified elsewhere.

As perinatal mortality is known to show associations with such factors as social class, parity, ethnic group, legitimacy, age, multiplicity of the pregnancy, and height it was essential to consider the extent to which these factors might have accounted for the observed differences. For example, high parity and illegitimacy have been 
associated with high perinatal loss in national studies, and we found that Asian patients in Leicestershire have an increased risk of perinatal death when compared with non-Asian patients. ${ }^{7}$ In order to remove any effect of social class on the estimates of risk we made subsequent calculations by comparing the leatherworkers, who are described as social class III manual, with other social class III manual workers. The result (table III) was slightly to increase the risk estimate from $2 \cdot 0$ to $2 \cdot 1$. Table II shows that there were few differences between the leatherworkers having perinatal deaths and the social class III manual workers having perinatal deaths in terms of other maternal risk factors. The leatherworkers, however, did, for example, contain slightly more primiparous women (tending to increase their risk), though they had fewer Asian women (tending to reduce the risk).

The perinatal deaths were classified into the groups described by Wigglesworth. ${ }^{8}{ }^{9}$ In that classification the deaths are divided into (a) those with fatal congenital malformations; $(b)$ asphyxias in labour - defined as those infants who die in labour together with those born after 38 weeks of gestation who die in the first week; (c) macerated stillbirths-defined as deaths before the onset of labour; and, finally, $(d)$ immature infants-namely, those born before 38 weeks of gestation who die in the first week of life. Excess mortality in two of these four categories-namely, congenital malformations and macerated stillbirths-accounted for all the excess risk in the leatherworkers, even when compared with other manual workers of the same social class (table III). This pattern of mortality is probably that which would be seen after maternal exposure to an embryotoxic agent.

When the congenital malformations were considered in detail they included three chromosomal abnormalities, confirmed by chromosomal analysis, each of the comparatively uncommon trisomy 18 (Edwards' syndrome). We estimate from other sources that in the period of the study some 1200 births occurred in Leicestershire to leatherworkers, giving an incidence of one in 400 births. Trisomy 18, however, is reported to occur only once in every $5000^{10}$ to 7000 births. ${ }^{11}$

A similar overall pattern of excess risk was also found when the analysis was stratified for area of residence. The excess occurred in all towns within the county where shoe manufacture took place. The geographical areas were defined by postcode areas using the first three digits of the postcode as a stratification variable.

TABLE I-Occupational order and odds in favour of perinatal death in working women in Leicestershire, 1976-82 (95 ${ }_{0}^{\circ}$ confidence limits in parentheses)

$$
\text { Occupational order }
$$

Odds ratio

\begin{tabular}{lll}
\hline VII & Engineering and allied trades workers NEC: other workers & $1 \cdot 8: 1 \cdot 0(5 \cdot 4-0 \cdot 6)$ \\
IX & Leatherworkers: other workers & $2 \cdot 0: 1 \cdot 0(3 \cdot 6-1 \cdot 1)$ \\
XIV & Makers of other products: other workers & $1 \cdot 8: 1 \cdot 0(4 \cdot 5-0 \cdot 8)$ \\
XXIII & Service, sport, and recreation workers: other workers & $1 \cdot 2: 1 \cdot 0(1 \cdot 6-0 \cdot 8)$
\end{tabular}

\section{Discussion}

Early reports disclosed an excess of nasal cancer in the leather industry, ${ }^{12}$ while the Atlas of Cancer Mortality ${ }^{13}$ reported a non-significant excess of nasal cancer in women in Leicestershire. Such occupational risks are often difficult to identify, particularly if the outcome of the exposure is not expressed until many years later. Detailed monitoring of outcomes of pregnancy provide a comparatively rapid and controllable way in which to assess major risks to the fetus. Unfortunately, most evidence in man to date has come as a result of industrial or environmental accidents with gross overexposure. ${ }^{2}$

We reviewed 27 occupational groups or orders, so that the initial observation of a significantly high risk of perinatal mortality in this group of workers was likely to have occurred by chance. Subsequent analysis, however, showed that $(a)$ even when adjustment for social class was made the risk was twice that expected; $(b)$ the excess perinatal mortality was not explained by age, parity, legitimacy, ethnic group, or height of the women leatherworkers; (c) the excess risk could be shown in all parts of the county where footwear was manufactured; and $(d)$ the excess risk in leatherworkers was concentrated entirely within two of the four categories of perinatal deathsnamely, congenital malformations and macerated stillbirthsand included an excess of trisomy 18.

Most women in the footwear industry enter the trade after leaving school and if the work is initially acceptable they tend to stay. There appears to be little casual, short term work in the industry. The women work predominantly in the closing rooms, where the uppers of shoes are made. The processes entail sedentary work using various machines for cutting, shaping, sewing, marking, and sticking the component parts. The possible hazards would appear to be the leather or adhesives or both. While many of the adhesives are latex based, urethane adhesives, silicone sprays, and ethyl acetate are all widely used. Further investigations are needed to confirm this association which pay particular attention to occupational exposures before and during pregnancy. Appropriate advice might then be provided before pregnancy which might prevent fetal loss.

We thank John MacVicar, David Clayton, and Ian Young for their advice in preparing this paper, and all the Leicestershire staff, particularly midwives, who helped with the collection of data. The study is funded by the Leicestershire Health Authority.

TABLE II-Possible confounding factors in leatherworkers and other social class III manual workers. Perinatal deaths and live birth controls, Leicestershire, 1976-82

\begin{tabular}{|c|c|c|c|c|c|c|c|c|c|}
\hline \multirow{3}{*}{ Factor } & \multicolumn{4}{|c|}{ Leatherworkers } & \multicolumn{4}{|c|}{ Other social class III manual workers } & \multirow{3}{*}{$\begin{array}{l}\text { Odds ratio } \\
(a / b \div c / d)\end{array}$} \\
\hline & \multicolumn{2}{|c|}{ Perinatal deaths } & \multicolumn{2}{|c|}{ Live births } & \multicolumn{2}{|c|}{ Perinatal deaths } & \multicolumn{2}{|c|}{ Live births } & \\
\hline & $0_{1}$ & No $(a)$ & $o_{0}$ & No $(b)$ & ${ }_{0}^{\circ}$ & No $(c)$ & ${ }_{0}^{\circ}$ & No $(d)$ & \\
\hline $\begin{array}{l}\text { Parity }\left\{\begin{array}{l}0 \\
1-2 \\
23\end{array}\right. \\
\text { Asian ethnic group } \\
\text { Illegitimate } \\
\text { Singleton births }\end{array}$ & $\begin{array}{r}77 \cdot 8 \\
19 \cdot 4 \\
2 \cdot 8 \\
22 \cdot 2 \\
25 \cdot 0 \\
86 \cdot 1\end{array}$ & $\begin{array}{r}28 \\
7 \\
1 \\
8 \\
9 \\
31\end{array}$ & $\begin{array}{r}72 \cdot 2 \\
22 \cdot 2 \\
5 \cdot 6 \\
11 \cdot 1 \\
16 \cdot 7 \\
94 \cdot 4 \\
\end{array}$ & $\begin{array}{r}13 \\
4 \\
1 \\
2 \\
3 \\
17 \\
\end{array}$ & $\begin{array}{l}71 \cdot 3 \\
25 \cdot 2 \\
3 \cdot 5 \\
30 \cdot 0 \\
25 \cdot 3 \\
93 \cdot 1\end{array}$ & $\begin{array}{r}62 \\
22 \\
3 \\
26 \\
22 \\
81\end{array}$ & $\begin{array}{r}71.0 \\
24.7 \\
4.3 \\
11.8 \\
11.8 \\
98.9 \\
\end{array}$ & $\begin{array}{l}66 \\
23 \\
4 \\
11 \\
11 \\
92\end{array}$ & $\begin{array}{l}2 \cdot 3 \\
1 \cdot 7 \\
1 \cdot 7 \\
1 \cdot 5 \\
2 \cdot 1 \\
\end{array}$ \\
\hline Total & $100 \cdot 0$ & 36 & $100 \cdot 0$ & 18 & $100 \cdot 0$ & 87 & $100 \cdot 0$ & 93 & $2 \cdot 1$ \\
\hline $\begin{array}{l}\text { Mean maternal height }(\mathrm{cm}) \\
\text { Mean age (years) }\end{array}$ & \multicolumn{2}{|c|}{$\begin{array}{r}157 \cdot 0 \\
23.5\end{array}$} & \multicolumn{2}{|c|}{$\begin{array}{r}158.9 \\
23.6\end{array}$} & \multicolumn{2}{|c|}{$\begin{array}{r}157 \cdot 7 \\
24 \cdot 3\end{array}$} & \multicolumn{2}{|c|}{$\begin{array}{r}159 \cdot 7 \\
24 \cdot 6\end{array}$} & \\
\hline
\end{tabular}

TABLE III-Odds ratio of perinatal deaths by cause in leatherworkers compared with other social class III manual workers, Leicestershire, 1976-82

\begin{tabular}{|c|c|c|c|c|c|c|}
\hline & All deaths & Congenital malformations & Macerated stillbirths & Asphyxia in labour & Immaturity & Live births \\
\hline $\begin{array}{l}\text { Leatherworkers } \\
\text { Other social class III manual workers } \\
\text { Odds ratio for perinatal death } \\
95 \% \text { Confidence interval }\end{array}$ & $\begin{array}{c}36 \\
87 \\
2 \cdot 1: 1 \cdot 0 \\
4 \cdot 1-1 \cdot 1\end{array}$ & $\begin{array}{l}12 \\
20 \\
3 \cdot 1: 1 \cdot 0 \\
7 \cdot 6-1 \cdot 3\end{array}$ & $\begin{array}{c}17 \\
34 \\
2 \cdot 6: 1 \cdot 0 \\
5 \cdot 7-1 \cdot 2\end{array}$ & $\begin{array}{c}2 \\
13 \\
0 \cdot 8: 1 \cdot 0\end{array}$ & $\begin{array}{c}5 \\
20 \\
1 \cdot 3: 1 \cdot 0\end{array}$ & $\begin{array}{l}18 \\
93\end{array}$ \\
\hline
\end{tabular}




\section{References}

1 Chamberlain G, Garcia J. Pregnant women at work. Lancet 1983;i:228-30. Barlow SM, Sullivan FM. Reproductive hazards of industrial chemicals. London Academic Press, 1982

3 Hemminki K, Saloniemi I, Luoma K, et al. Transplacental carcinogens and mutagens: childhood cancer, malformations, and abortions as risk indicators. f Toxicol Environ Health 1980;6:1115-27.

4 Clarke M, Clayton DG. The design and interpretation of case-control studies of perinatal mortality. Am f Epidemiol 1981;113:636-45.

Surveys Classification of occupations. London: HMSO, 1970

Statistical Office. Social trends. No 14. London: HMSO, 1983.

, Clayton DG. Quality of obstetric care provided for Asian immigrants in Leicestershire. $\mathrm{Br}$ Med $\mathcal{f} 1983 ; 286: 621-3$
8 Wigglesworth JS. Monitoring perinatal mortality, a pathophysiological approach. Lancet 1980 ;ii :684-6.

larke $M$. Perinatal audit: a tried and tested epidemiological method. Community

. Prevalence of Edwards' syndrome. Clustering and seasonal variation? Hum Genet $1975 ; 26: 113-6$.

11 Taylor AI. Autosomal trisomy syndromes: a detailed study of 27 cases of Edwards' syndrome and 27 cases of Patau's syndrome. $¥$ Med Genet 1968;5: $227-41$

12 Acheson ED. Nasal cancer in the Northamptonshire boot and shoe industry.

13 Gardner MJ, Winter PD, Taylor CP, Acheson ED. Atlas of cancer mortality Chichester: John Wiley and Son Ltd, 1983.

\begin{abstract}
A 31 year old woman in whom subarachnoid and intracerebral haemorrhage occurred during the second trimester of pregnancy was sustained in intensive care with a respirator for 10 weeks. Computed tomography of the brain showed bilateral intraventricular haemorrhages. Because of drug resistant hypotonic episodes at 31 weeks' gestation caesarean section was performed, and a boy was delivered. The woman died of spontaneous cardiac arrest two days after caesarean section, and the boy showed normal development.
\end{abstract}

Life support can be continued for several weeks in a modern intensive care unit after fatal insult to the brain even in a pregnant woman without affecting the fetus.

\section{Introduction}

Improved life support with modern techniques has increased the possibility of prolonging pregnancy in mothers with acute fatal illness. Sometimes one or two weeks' life support is enough for the fetus to survive. Fatal maternal illness during the first or second trimester of pregnancy causes medical, ethical, and legal problems. There is no routine practice for obstetric or perinatal management of pregnancy in these cases. We report a case of

Department of Obstetrics and Gynaecology, University of Oulu, SF 90220 Oulu 22, Finland

J E HEIKKINEN, MD, assistant professor

P P KIRKINEN, MD, senior lecturer

P A JARVINEN, MD, professor

Department of Neurology, University of Oulu

R I RINNE, MD, assistant neurologist

$\mathrm{K}$ A SOTANIEMI, MD, senior lecture

Department of Anaesthesia, University of Oulu

S M ALAHUHTA, MD, assistant anaesthesiologist

L S NUUTINEN, MD, senior lecturer

Department of Medicine, University of Oulu

J A J LUMME, MD, assistant physician

Department of Paediatrics, University of Oulu

M E KOIVISTO, MD, senior lecturer

Correspondence to: Dr J E Heikkinen. successful life support for 10 weeks in a mother with fatal subarachnoid and intracerebral haemorrhage during the second trimester of pregnancy.

\section{Case history and initial neurological findings}

The patient was a 31 year old woman, gravida 4, para 3. She had no history of neurological disease, and her previous pregnancies had been normal. The present pregnancy had been uncomplicated until she sustained acute severe headache and nausea at the beginning of the 21 st week of gestation. After a few hours she lost consciousness, which was never recovered. In the ambulance spontaneous respiration stopped, and she was ventilated manually for about 40 minutes until it was possible to intubate her and connect her to a respirator. During transport she was hypotonic (systolic blood pressure $50-60 \mathrm{~mm} \mathrm{Hg}$ ) but her pulse rate was regular.

On admission to hospital her pulse rate was 100 beats/min and her blood pressure $100 / 60 \mathrm{~mm} \mathrm{Hg}$. She was deeply unconscious and unresponsive to pain, with flaccid tetraplegia. Her pupils were maximally dilated and pupillary reflexes were absent. On funduscopy bilateral papilloedema and retinal haemorrhage were found. Computed tomography of the brain showed bilateral intraventricular haemorrhages, a large intracerebral haemorrhage (size $52 \times 30 \times 47 \mathrm{~mm}$ ) in the left frontoparietal region, and bilateral small haematomas in the area of the capsula interna. The midline of the brain was displaced about $15 \mathrm{~mm}$ to the right. Her clinical condition was grade 5, according to the criteria of Hunt and Hess, ${ }^{1}$ and so there were no grounds for operative treatment. She was connected to a volume controlled respirator, and dexamethasone treatment was started to decrease brain pressure.

On the second day in hospital her temperature decreased to $33^{\circ} \mathrm{C}$, but it later stabilised at about $35^{\circ} \mathrm{C}$. At neurological examination only the corneal reflexes could be elicited by a strong stimulus. On and after the fourth day all brain stem reflexes (pupillary, oculocephalic, oculovestibular, corneal, and swallowing) were absent. An apnoea test was not performed because of the living fetus. $\mathrm{Her}$ clinical condition remained unchanged. The first electroencephalogram, obtained on the second day in hospital, showed occasional slight activity in the temporobasal region; the second electroencephalogram, obtained the next day, showed slight and temporary theta activity in the frontotemporal region. On the fourth day the electroencephalogram was isoelectric. One week later there was slight activity in the right parieto-occipital area. This finding remained constant and was also registered one day after caesarean section.

\section{Later course and management}

Although the maternal prognosis was considered to be hopeless and no spontaneous breathing was present, intensive care with the 